\title{
MODIS observed phytoplankton dynamics in the Taiwan Strait: an absorption-based analysis
}

\author{
S. Shang ${ }^{1}$, Q. Dong ${ }^{1,2}$, Z. Lee ${ }^{2}$, Y. Li ${ }^{1}$, Y. Xie ${ }^{1}$, and M. Behrenfeld ${ }^{3}$ \\ ${ }^{1}$ State Key Laboratory of Marine Environmental Science, Xiamen University, Xiamen 361005, Fujian, China \\ ${ }^{2}$ Geosystems Research Institute, Mississippi State University, MS 39529, USA \\ ${ }^{3}$ Department of Botany and Plant Pathology, Oregon State University, OR 97333, USA
}

Received: 25 September 2010 - Published in Biogeosciences Discuss.: 27 October 2010

Revised: 20 March 2011 - Accepted: 29 March 2011 - Published: 6 April 2011

\begin{abstract}
This study used MODIS observed phytoplankton absorption coefficient at $443 \mathrm{~nm}$ (Aph) as a preferable index to characterize phytoplankton variability in optically complex waters. Aph derived from remote sensing reflectance ( $R_{\mathrm{rs}}$, both in situ and MODIS measured) with the QuasiAnalytical Algorithm (QAA) were evaluated by comparing them with match-up in situ measurements, collected in both oceanic and nearshore waters in the Taiwan Strait (TWS). For the data with matching spatial and temporal window, it was found that the average percentage error $(\varepsilon)$ between MODIS derived Aph and field measured Aph was 33.8\% $(N=30$, Aph ranges from 0.012 to $0.537 \mathrm{~m}^{-1}$ ), with a root mean square error in log space (RMSE_log) of 0.226. By comparison, $\varepsilon$ was $28.0 \%(N=88$, RMSE_log $=0.150)$ between Aph derived from ship-borne $R_{\mathrm{rs}}$ and Aph measured from water samples. However, values of $\varepsilon$ as large as $135.6 \%(N=30$, RMSE $\_$log $=0.383$ ) were found between MODIS derived chlorophyll- $a$ (Chl, OC3M algorithm) and field measured Chl. Based on these evaluation results, we applied QAA to MODIS $R_{\mathrm{rs}}$ data in the period of 2003-2009 to derive climatological monthly mean Aph for the TWS. Three distinct features of phytoplankton dynamics were identified. First, Aph is low and the least variable in the Penghu Channel, where the South China Sea water enters the TWS. This region maintains slightly higher values in winter $(\sim 17 \%$ higher than that in the other seasons) due to surface nutrient entrainment under winter wind-driven vertical mixing. Second, Aph is high and varies the most in the mainland nearshore water, with values peaking in summer (June-August) when river plumes and coastal upwelling enhance surface nutrient loads. Interannual variation of bloom intensity in Hanjiang River estu-
\end{abstract}

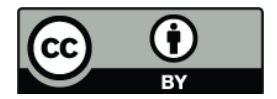

Correspondence to: S. Shang (slshang@gmail.com) ary in June is highly correlated with alongshore wind stress anomalies, as observed by QuikSCAT. The year of minimum and maximum bloom intensity is in the midst of an El Niño and a La Niña event, respectively. Third, a high Aph patch appears between April and September in the middle of the southern TWS, corresponding to high thermal frontal probabilities, as observed by MODIS. Our results support the use of satellite derived Aph for time series analyses of phytoplankton dynamics in coastal ocean regions, whereas satellite $\mathrm{Chl}$ products derived empirically using spectral ratio of $R_{\mathrm{rs}}$ suffer from artifacts associated with non-biotic optically active materials.

\section{Introduction}

While the concentration of phytoplankton pigments in the surface ocean reflect both variability in phytoplankton standing stocks and physiological state (e.g. Behrenfeld et al., 2005; Westberry et al., 2008), it has a clear impact on the optical properties of the water, allowing its relatively straight-forward retrieval from remote sensing measurements (e.g. Sathyendranath et al., 1994). The most common pigment product retrieved from ocean color remote sensing is chlorophyll- $a$ concentration (Chl, $\mathrm{mg} \mathrm{m}^{-3}$; frequently used symbols throughout the manuscript are summarized in Table 1). However, because of the optical complexity in nearshore waters (Carder et al., 1989; Zhang et al., 2006) and the simple spectral ratio approach (O'Reilly et al., 2000) used for the derivation of $\mathrm{Chl}$, Chl product can be problematic in optically complex nearshore waters. Alternatively, analytical approaches (IOCCG, 2006) based on the radiative transfer theory have been developed to retrieve the spectral absorption coefficient of phytoplankton $\left(a_{\mathrm{ph}}, \mathrm{m}^{-1}\right)$. Using phytoplankton absorption, instead of $\mathrm{Chl}$, as a superior metric

Published by Copernicus Publications on behalf of the European Geosciences Union. 
Table 1. Symbols, abbreviations and description.

\begin{tabular}{lll}
\hline Symbol & Description & Unit \\
\hline ABI & Areal Bloom Index & $\mathrm{m}^{-1}$ \\
$a_{\mathrm{ph}}$ & $\begin{array}{l}\text { Absorption coefficient of phytoplank- } \\
\text { ton; } a_{\mathrm{ph}}(412) \text { means } a_{\mathrm{ph}} \text { at } 412 \mathrm{~nm} ;\end{array}$ & $\mathrm{m}^{-1}$ \\
& $\begin{array}{l}a_{\mathrm{ph}}(443) \text { means } a_{\mathrm{ph}} \text { at } 443 \mathrm{~nm} \\
\text { Aph }\end{array}$ & $a_{\mathrm{ph}}(443)$ \\
$a_{\mathrm{t}-\mathrm{w}}$ & Total absorption without pure water & $\mathrm{m}^{-1}$ \\
& $\begin{array}{l}\text { contribution; } a_{\mathrm{t}-\mathrm{w}}(443) \text { means } a_{\mathrm{t}-\mathrm{w}} \\
\text { at } 443 \mathrm{~nm}\end{array}$ & \\
Chl & Chlorophyll- $a$ concentration & $\mathrm{mg} \mathrm{m}^{-3}$ \\
MEI & Multivariate ENSO Index & \\
QAA & Quasi-analytical Algorithm & \\
& (Lee et al., 2002) & \\
RMSE & Root mean square error & $\mathrm{sr}^{-1}$ \\
$R_{\mathrm{rs}}$ & Remote sensing reflectance & \\
TWS & Taiwan Strait & \\
\hline
\end{tabular}

of phytoplankton pigmentation is becoming increasingly accepted (e.g. Cullen, 1982; Marra et al., 2007), especially from the remote sensing point of view (Lee et al., 1996; Hirawake et al., 2011). This is because the direct controller of ocean color is the spectral absorption and scattering properties of the water media (e.g. Gordon et al., 1988) rather than pigment concentrations, although the variations of the latter will change pigment absorption in a non-stable fashion (e.g. Bricaud et al., 1998; Stuart et al., 1998). However, few studies based on in situ measurements exist to test whether $a_{\mathrm{ph}}$ can be derived from satellite ocean color data with less uncertainty than Chl. Such evidence is vital in order to confirm that $a_{\mathrm{ph}}$ can function as the preferable index for characterizing phytoplankton variability in the upper ocean. Here we provide results conducted over the Taiwan Strait (TWS), a shallow shelf channel that connects the South China Sea with the East China Sea (see Fig. 1), to demonstrate that (1) phytoplankton absorption can be retrieved more accurately than chlorophyll- $a$ in this optically complex ocean region from satellite observed ocean color and (2) changes of phytoplankton absorption capture phytoplankton dynamics in a vibrant and changing environment.

The TWS has complex hydrographic conditions determined by the relative influence of the South China Sea Warm Current (SCSWC) and the Kuroshio Branch Water (KBW), which are warm, saline, and oligotrophic, and the Zhe-Min Coastal Water (ZMCW), which is cold, fresh, and eutrophic, and varies seasonally in response to changes in the monsoonal wind (e.g. Jan et al., 2002). Several medium-sized rivers (e.g. Hanjiang and Jiulongjiang Rivers) are located on the western coast (mainland China) of the strait. Also along this coast, upwelling develops in summer, driven by the prevailing southwest monsoon which runs parallel to the coast

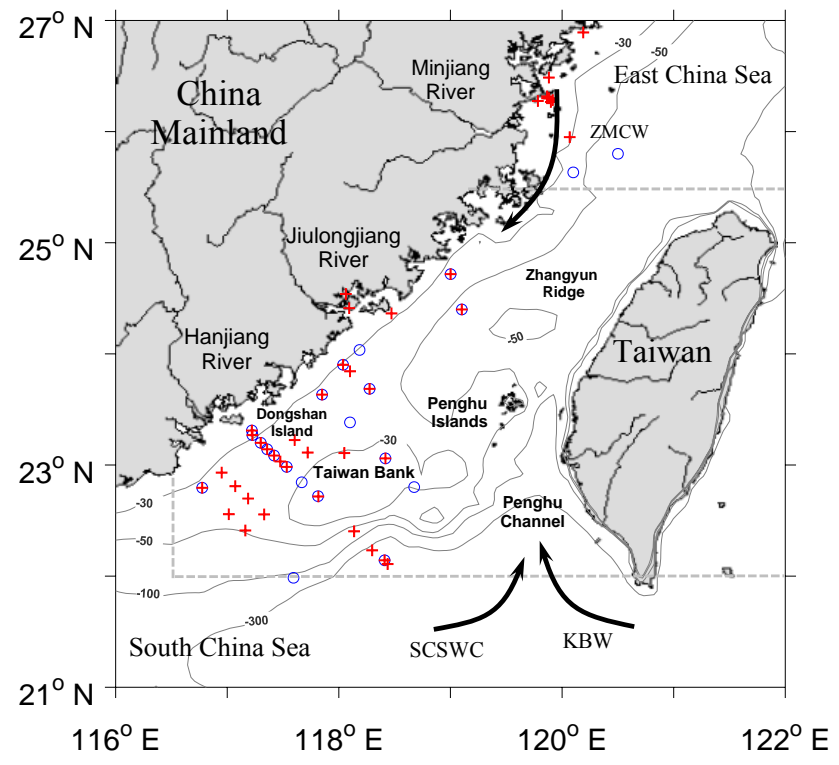

Fig. 1. Map of the Taiwan Strait; ZMCW: Zhe-Min Coastal Water; SCSWC: South China Sea Warm Current; KBW: Kuroshio Branch Water; the red cross and blue circle symbols show the locations where field measured $R_{\mathrm{rs}}$ and MODIS $R_{\mathrm{rs}}$ have match-up in situ observed absorption coefficients, respectively; the grey lines indicate the boundaries of the research area of this study.

due to Ekman transport (e.g. Hong et al., 2009). Different waters converge in a limited area with a shallow bank (Taiwan Bank), a ridge (Zhangyun Ridge), and deep channel (Penghu Channel), creating strong frontal phenomena (e.g. Chang et al., 2006; Li et al., 2006).

For this study, we first derived $a_{\mathrm{ph}}$ from remote sensing reflectance $\left(R_{\mathrm{rs}}, \mathrm{sr}^{-1}\right)$ with the quasi-analytical bio-optical inversion algorithm (QAA, Lee et al., 2002, 2009). In addition to QAA, there are several algorithms available for the retrieval of absorption and backscattering coefficients from $R_{\mathrm{rS}}$ (IOCCG, 2006). Here we used QAA because of its transparency in the analytical inversion process and simplicity in implementation. We evaluated the $R_{\mathrm{rs}}$ derived $a_{\mathrm{ph}}$ by comparing it with match-up in situ measured $a_{\mathrm{ph}}$ collected in both oceanic and nearshore waters in the TWS. Finally we applied QAA to MODIS $R_{\mathrm{rs}}$ data for the period 2003-2009 to derive climatological monthly mean $a_{\mathrm{ph}}$ at $443 \mathrm{~nm}\left(a_{\mathrm{ph}}(443)\right.$; also represented as Aph for brevity) and to evaluate spatiotemporal variation of the mean Aph in the TWS.

\section{Data and methods}

\subsection{Satellite data}

Aqua-MODIS daily Level-2 normalized water leaving radiance (nLw, $\mathrm{W} \mathrm{m}^{-2} \mathrm{~nm}^{-1} \mathrm{sr}^{-1}, 2005$ reprocessed version) data were obtained from the NASA Distributed Active Archive Center (http://oceancolor.gsfc.nasa.gov/) and 
were subsequently converted to $R_{\mathrm{rs}}$ via the ratio of $\mathrm{nLw}$ to extra-terrestrial solar irradiance, $F_{0}\left(\mathrm{~W} \mathrm{~m}^{-2} \mathrm{~nm}^{-1}\right)$ (Gordon, 2005; also see http://oceancolor.gsfc.nasa.gov/DOCS/ RSR_tables.html). Aqua-MODIS Level-2 Chl daily data during 2003-2009, which were derived by using the OC3M empirical algorithm (O'Reilly et al., 2000), were also obtained from the same source. These data were further processed into Level-3 products by using Mercator projection, which was implemented on SeaDAS (http://seadas.gsfc.nasa.gov/ doc/tutorial/sds_tut2.html). The spatial resolution of these data was $1 \mathrm{~km}$ by $1 \mathrm{~km}$.

Daily wind field data were obtained from QuikScatterometer (QuikSCAT) observations from 2003 to 2009 (http:// podaac.jpl.nasa.gov), with a spatial resolution of $0.25^{\circ}$ by $0.25^{\circ}$ (equivalent to $\sim 25 \mathrm{~km}$ by $\sim 25 \mathrm{~km}$ ). Daily wind stress $\left(T, \mathrm{~N} \mathrm{~m}^{-2}\right)$ was calculated from (Stewart, 2008):

$T=\rho_{\mathrm{a}} C_{\mathrm{D}} U_{10}^{2}$

where $\rho_{\mathrm{a}}=1.3 \mathrm{~kg} \mathrm{~m}^{-3}$ was the density of air, $U_{10}\left(\mathrm{~m} \mathrm{~s}^{-1}\right)$ was wind speed at $10 \mathrm{~m}$ above the sea surface (the QuiSCAT measurement), and $C_{\mathrm{D}}$ was the drag coefficient. $C_{\mathrm{D}}$ was calculated from Yelland and Taylor (1996) and Yelland et al. (1998). Wind stress vectors were further decomposed into alongshore (southwesterly) and cross-shore (northwesterly) components by applying a simple vector manipulation.

Aqua-MODIS sea surface temperature $\left(\mathrm{SST},{ }^{\circ} \mathrm{C}\right)$ monthly mean data ( $4 \mathrm{~km}$ by $4 \mathrm{~km}$ resolution) during 2003-2009 were downloaded from http://oceandata.sci.gsfc.nasa.gov/. Based on this SST data, we derived a thermal frontal probability map for the TWS by following Wang et al. (2001). Briefly, we calculated the SST gradients in eight directions for each clear pixel and chose the average over the three absolute maxima as the horizontal gradient for this pixel. Only pixels whose gradients were equal to or greater than the threshold of $0.5^{\circ} \mathrm{C}$ per $4 \mathrm{~km}$ were regarded as frontal pixels. The frontal probability was then obtained by dividing the number of observations the pixel was frontal, by the accumulative number of observationsthe pixel had a valid SST value.

\subsection{Calculation of mean and anomaly}

To address spatio-temporal variations of properties derived from satellite measurements, temporal and spatial means and anomalies were calculated for each property. These properties included the non-water absorption at $443 \mathrm{~nm}$ (total absorption coefficient without contribution from pure water; $\left.a_{\mathrm{t}-\mathrm{w}}(443), \mathrm{m}^{-1}\right)$ and Aph from QAA_v5, Chl from OC3M, and QuikSCAT derived alongshore component of wind stress.

For pixel $i$ in month $X$ year $Y$, the monthly mean of a property was obtained by adding up all the available daily values in the month and then dividing them by the number of days having valid values. The spatial mean of each property in month $X$ year $Y\left(\bar{P}_{X, Y}\right)$ was calculated by adding up all the available monthly mean values in the TWS area in the month and dividing them by the number of pixels having valid retrievals. The TWS area was defined as the ocean area between the China mainland coast or the $116.5^{\circ} \mathrm{E}$ longitude and the $122^{\circ} \mathrm{E}$, and between $22^{\circ} \mathrm{N}$ and $25.5^{\circ} \mathrm{N}$ (see Fig. 1, the area enclosed by the dashed grey lines, the mainland coastline and the $122^{\circ} \mathrm{E}$ ).

For pixel $i$ in month $X$, the climatological monthly mean of a property $\left(\bar{P}_{i, X}\right)$ was calculated by adding up all the monthly values for 2003-2009 and then dividing them by the number of years $(=7)$. The spatial mean of each property in month $X\left(\bar{P}_{X}\right)$ was then calculated based on this climatological monthly mean dataset following the above mentioned procedure for calculation of $\bar{P}_{X, Y}$.

The spatial anomaly of a property in pixel $i$ month $X$ was derived from $\bar{P}_{i, X}-\bar{P}_{X}$. The temporal anomaly of a property in month $X$ year $Y$ was calculated from $\bar{P}_{X, Y}-\bar{P}_{X}$.

\subsection{In situ data}

\subsubsection{Remote sensing reflectance}

In stiu $R_{\mathrm{rs}}$ was derived from measured (1) upwelling radi-

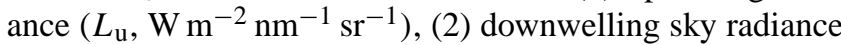
( $L_{\mathrm{sky}}, \mathrm{W} \mathrm{m}^{-2} \mathrm{~nm}^{-1} \mathrm{sr}^{-1}$ ), and (3) radiance from a standard Spectralon reflectance plaque ( $\left.L_{\text {plaque }}, \mathrm{W} \mathrm{m}^{-2} \mathrm{~nm}^{-1} \mathrm{sr}^{-1}\right)$. The instrument used was the GER 1500 spectroradiometer (Spectra Vista Corporation, USA), which covers a spectral range of $350-1050 \mathrm{~nm}$ with a spectral resolution of $3 \mathrm{~nm}$. From these three components, $R_{\mathrm{rs}}$ was calculated as:

$R_{\mathrm{rs}}=\rho\left(L_{\mathrm{u}}-F \cdot L_{\mathrm{sky}}\right) /\left(\pi \cdot L_{\text {plaque }}\right)-\Delta$

where $\rho$ is the reflectance $(0.5)$ of the spectralon plaque with Lambertian characteristics and $F$ is surface Fresnel reflectance (around 0.023 for the viewing geometry). $\Delta$ $\left(\mathrm{sr}^{-1}\right)$ accounts for the residual surface contribution (glint, etc.), which was determined either by assuming $R_{\mathrm{rs}}(750)=0$ (clear oceanic waters) or through iterative derivation according to optical models for coastal turbid waters as described in Lee et al. (2010a).

\subsubsection{Field-measured absorption coefficients and chlorophyll- $a$}

Water samples for determination of absorption coefficients and Chl were collected from surface waters during 2003 2007 in the TWS. Sampling station depths ranged from $\sim 10 \mathrm{~m}$ to $\sim 400 \mathrm{~m}$. Measurements of chromophoric dissolved organic matter (CDOM) absorption coefficient, $a_{\mathrm{g}}$ $\left(\mathrm{m}^{-1}\right)$, and Chl were performed according to the Ocean Optics Protocols Version 2.0 (Mitchell et al., 2000), and were detailed in Hong et al. (2005) and Du et al. (2010). Particulate absorption coefficient $\left(a_{\mathrm{p}}, \mathrm{m}^{-1}\right)$ was measured by the filter-pad technique (Kiefer and SooHoo, 1982) with a dualbeam PE Lambda 950 spectrophotometer equipped with an integrating sphere $(150 \mathrm{~mm}$ in diameter) following a modified Transmittance-Reflectance (T-R) method (Tassan and 
Ferrari, 2002; Dong et al., 2008). This approach was used instead of the T method recommended in the NASA protocol (Mitchell et al., 2000) because some of the samples were collected nearshore. These samples were rich in highly scattered non-pigmented particles. The standard T-method will thus cause an overestimate of sample absorption (Tassan and Ferrari, 1995). Detrital absorption $\left(a_{\mathrm{d}}, \mathrm{m}^{-1}\right)$ was therefore obtained by repeating the modified T-R measurements on samples after pigment extraction by methanol (Kishino et al., 1985). $a_{\mathrm{ph}}$ was then calculated by subtracting $a_{\mathrm{d}}$ from $a_{\mathrm{p}}$, and the combination of $a_{\mathrm{p}}$ and $a_{\mathrm{g}}$ yields an estimate of $a_{\mathrm{t}-\mathrm{w}}$.

Combining all the field studies, we collected 104 sets of in situ data, with each set including $a_{\mathrm{t}-\mathrm{w}}, a_{\mathrm{ph}}, a_{\mathrm{d}}, a_{\mathrm{g}}$ and Chl. This in situ dataset covered a wide range of absorption properties, with $a_{\mathrm{t}-\mathrm{w}}(443)$ ranging from 0.019 to $2.41 \mathrm{~m}^{-1}$, and the $\mathrm{Aph} / a_{\mathrm{t}-\mathrm{w}}(443)$ ratio varying between $9-86 \%$.

Due to frequent cloud cover in the TWS, only 30 matching data pairs were achieved of in situ absorption and $\mathrm{Chl}$ data collected within \pm 24 h of MODIS overpass (Fig. 1, circle symbols). By comparison, there were 88 sets of in situ absorption and Chl data having match-up in situ $R_{\mathrm{rs}}$ measurements (Fig. 1, cross symbols).

\section{Evaluation of $\boldsymbol{R}_{\mathrm{rs}}$ derived absorption coefficients in the Taiwan Strait}

$R_{\mathrm{rs}}$ from field measurements and MODIS were fed to QAA_v5 (Lee et al., 2009), respectively, to derive two sets of $a_{\mathrm{t}-\mathrm{w}}$ and $a_{\mathrm{ph}}$. In order to evaluate the quality of $R_{\mathrm{rs}}$ derived $a_{\mathrm{ph}}$, we used the root mean square error both in linear scale (RMSE) and in log scale (RMSE_log) and averaged percentage error $(\varepsilon)$ as a measure to describe the similarity/difference between the field measured $(f)$ and retrieved data sets $(r)$ :

$\varepsilon=\left(\frac{1}{n} \sum_{i=1}^{n}\left|\frac{r_{i}-f_{i}}{f_{i}}\right|\right) \cdot 100 \%$

$\mathrm{RMSE}=\sqrt{\frac{1}{n} \sum_{i=1}^{n}\left(r_{i}-f_{i}\right)^{2}}$

RMSE_log $=\sqrt{\frac{1}{n} \sum_{i=1}^{n}\left(\log \left(r_{i}\right)-\log \left(f_{i}\right)\right)^{2}}$

Results are given in Table 2. Figure 2a and $\mathrm{b}$ compares the derived and measured $a_{\mathrm{t}-\mathrm{w}}$ and $a_{\mathrm{ph}}$ values at $443 \mathrm{~nm}$ for the MODIS (the yellow square symbols) and the in situ (the blue circle symbols) data sets, respectively.

Averaged percentage error $(\varepsilon)$ and RMSE_log between in situ measured $a_{\mathrm{ph}}(412)$ and MODIS $a_{\mathrm{ph}}(412)$ were $36.1 \%$ and 0.252 , respectively, for an $a_{\mathrm{ph}}(412)$ range of 0.009 $0.539 \mathrm{~m}^{-1}$. Similarly, $\varepsilon$ was $33.8 \%$ and RMSE $\_$log was 0.226 for an Aph range of $0.012-0.537 \mathrm{~m}^{-1}$ (Table 2). These
Table 2. Statistics results between derived and in situ absorption coefficients and Chl data*.

\begin{tabular}{|c|c|c|c|c|c|c|}
\hline \multicolumn{2}{|c|}{ Band (nm) } & RMSE & RMSE_log & $\varepsilon(\%)$ & $R^{2}$ & $n$ \\
\hline \multicolumn{7}{|c|}{ Derived from field measured $R_{\mathrm{rs}}(N=88)$} \\
\hline \multirow{4}{*}{$a_{\mathrm{t}-\mathrm{w}}(\lambda)$} & 412 & 0.269 & 0.155 & 26.1 & 0.80 & 88 \\
\hline & 443 & 0.197 & 0.135 & 23.1 & 0.87 & 88 \\
\hline & 488 & 0.079 & 0.117 & 22.4 & 0.93 & 88 \\
\hline & 531 & 0.040 & 0.169 & 37.7 & 0.91 & 88 \\
\hline \multirow{4}{*}{$a_{\mathrm{ph}}(\lambda)$} & 412 & 0.086 & 0.145 & 26.9 & 0.86 & 88 \\
\hline & 443 & 0.093 & 0.150 & 28.0 & 0.87 & 88 \\
\hline & 488 & 0.066 & 0.189 & 43.0 & 0.90 & 88 \\
\hline & 531 & 0.051 & 0.348 & 116.1 & 0.85 & 88 \\
\hline \multicolumn{2}{|l|}{ Chl } & 5.067 & 0.429 & 162.0 & 0.80 & 88 \\
\hline \multicolumn{7}{|c|}{ Derived from MODIS $R_{\mathrm{rs}}(N=30)$} \\
\hline \multirow{4}{*}{$a_{\mathrm{t}-\mathrm{w}}(\lambda)$} & 412 & 0.076 & 0.150 & 25.9 & 0.76 & 30 \\
\hline & 443 & 0.063 & 0.127 & 21.1 & 0.91 & 30 \\
\hline & 488 & 0.021 & 0.109 & 20.2 & 0.91 & 30 \\
\hline & 531 & 0.011 & 0.142 & 25.7 & 0.91 & 30 \\
\hline \multirow{4}{*}{$a_{\mathrm{ph}}(\lambda)$} & 412 & 0.078 & 0.252 & 36.1 & 0.87 & 25 \\
\hline & 443 & 0.070 & 0.226 & 33.8 & 0.86 & 25 \\
\hline & 488 & 0.019 & 0.265 & 34.8 & 0.87 & 28 \\
\hline & 531 & 0.012 & 0.267 & 63.5 & 0.88 & 26 \\
\hline \multicolumn{2}{|l|}{ Chl } & 2.063 & 0.383 & 135.6 & 0.81 & 30 \\
\hline
\end{tabular}

${ }^{*} N$ is the number of data tested, while $n$ is the number of valid retrievals.

errors decreased when $a_{\mathrm{ph}}$ was derived from ship-borne $R_{\mathrm{rs}}$. For example, the $\varepsilon$ was $28.0 \%$ and the RMSE_log was 0.150 for $443 \mathrm{~nm}$ (Table 2). Such a difference was not surprising since additional uncertainties were introduced in satellite match-ups that were associated with imperfections in atmospheric correction over coastal water for the MODIS $R_{\mathrm{rS}}$ (Dong, 2010) and the spatio-temporal mismatch between satellite and field data $\left(1 \mathrm{~km}^{2}\right.$ versus $1 \mathrm{~m}^{2}$, and the temporal window of $\pm 24 \mathrm{~h}$ ). Among the 88 ship-borne data, there were 26 collected from waters close to river estuaries. The RMSE log was 0.172 for Aph, suggesting that the retrievals of Aph are robust and not impacted by CDOM and detritus in the waters having strong influence of riverine inputs. All these results were better than the evaluation results reported in the IOCCG Report No. 5 (IOCCG, 2006), which used the earliest version of QAA (Lee et al., 2002). In that report, no satellite $R_{\mathrm{rs}}$ derived $a_{\mathrm{ph}}$ data were evaluated and the RMSE_log between in situ $R_{\mathrm{rs}}$ derived Aph and field measured Aph was 0.321 (it was 0.150 in this study). A recent evaluation of SeaWiFS $R_{\mathrm{rS}}$ derived Aph using QAA at an European coastal site produced a RMSE_log of 0.21 (Mélin et al., 2007), which was comparable to our results.

The difference between in situ measured $\mathrm{Chl}$ and matchup $R_{\mathrm{rs}}$ derived $\mathrm{Chl}$ (via OC3M) was much larger than found for Aph (Fig. 2c). Between in situ measured Chl and MODIS 

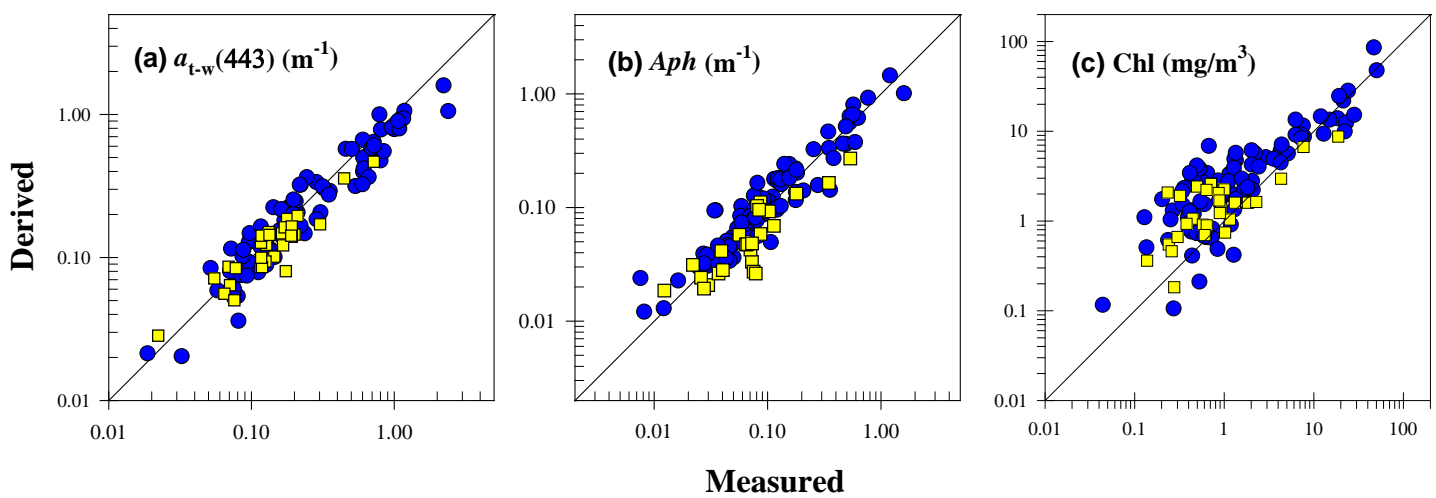

Fig. 2. Scatter plot of $R_{\mathrm{rs}}$ (in situ: blue circles; MODIS: yellow squares) derived (a) $a_{\mathrm{t}-\mathrm{w}}(443)$, (b) Aph and (c) Chl versus field measured data.

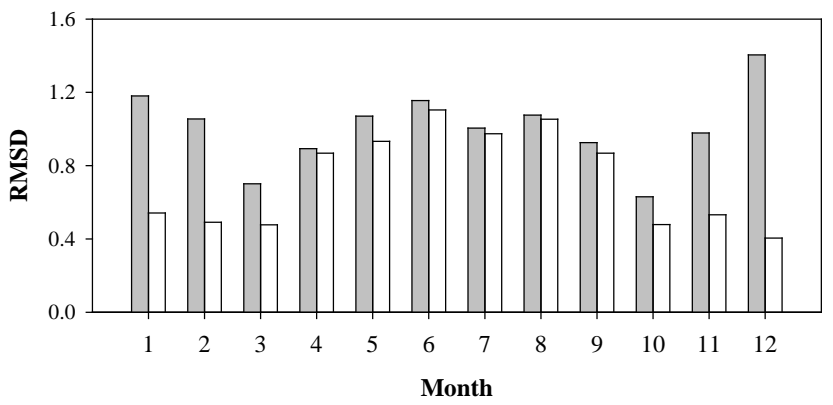

Fig. 3. Root mean square deviation between normalized spatial anomaly of Aph and that of Chl (the grey bar), and normalized spatial anomaly of $a_{\mathrm{t}-\mathrm{w}}(443)$ and that of Chl (the empty bar).

$R_{\mathrm{rs}}$ derived Chl, the $\varepsilon$ was $135.6 \%$ and RMSE_log was 0.383 . Between in situ measured Chl and in situ $R_{\mathrm{rs}}$ derived Chl, the $\varepsilon$ was $162.0 \%$ and RMSE_log was 0.429 . This analysis of match-up uncertainties clearly indicated improved performance of $R_{\mathrm{rs}}$-retrieved Aph over Chl in the TWS. One fundamental reason for such results is that $R_{\mathrm{rs}}$ is largely determined by the absorption and scattering properties of all the optically active materials in the water, of which phytoplankton is simply one of them (Mobley, 1994; IOCCG, 2006). Higher uncertainty associated with $\mathrm{Chl}$ is thus anticipated while trying to retrieve Chl by simple spectral ratio of $R_{\mathrm{rs}}$ in marine waters where the contribution of non-phytoplankton components is significant (e.g., TWS).

\section{Comparison of the spatial patterns of MODIS Aph and $a_{\mathrm{t}-\mathrm{w}}(443)$ with $\mathrm{Chl}$ in the Taiwan Strait}

The above analysis of match-up uncertainties supports the use of $R_{\mathrm{rs}}$ derived Aph as a preferable index (compared to $\mathrm{Chl}$ ) to represent phytoplankton in the optically complex coastal water of the TWS. A time series of MODIS Aph for the TWS was thus derived by inputting daily MODIS $R_{\mathrm{rS}}$ into
QAA_v5. Climatological monthly mean Aph during 20032009 were then derived, along with $a_{\mathrm{t}-\mathrm{w}}(443)$ from QAA_v5 and $\mathrm{Chl}$ from OC3M. Before using this multi-year monthly mean Aph dataset to address phytoplankton dynamics in the TWS, we did a further comparison of the spatial patterns of Aph and $a_{\mathrm{t}-\mathrm{w}}(443)$ with Chl for the entire TWS. This additional analysis was conducted to address a concern that the evaluation results shown in Sect. 3 were merely a comparison of discrete match-up samples in the TWS and most of the $R_{\mathrm{rs}}$ data used in the analysis were in situ measurements, rather than MODIS measurements, and, therefore, did not represent the spatially averaged light field that a satellite sensor detects. The spatial patterns of the three properties in the TWS were revealed by calculating their spatial anomalies and normalizing each to their respective spatial mean. The RMSD (root mean square deviation) between each normalized spatial anomaly pair of Chl and Aph or Chl and $a_{\mathrm{t}-\mathrm{w}}(443)$ was calculated as:

$\mathrm{RMSD}=\sqrt{\frac{1}{n} \sum_{i=1}^{n} \delta^{2}}$

where $\delta$ was the difference between each pair of normalized spatial anomalies, and $n$ was the pixel number (varies from 134000 to 148118 , depending on percentage of cloud cover in each month). As shown in Fig. 3, the RMSD was larger between $\mathrm{Chl}$ and Aph (the grey bar) than between $\mathrm{Chl}$ and $a_{\mathrm{t}-\mathrm{w}}(443)$ (the empty bar), especially during the cold season when the wind was strong and the water was relatively turbid due to sediment resuspension (Guo et al., 1991). This finding clearly indicates that the spatial pattern of empirically derived MODIS Chl was more similar to that of MODIS $a_{\mathrm{t}-\mathrm{w}}(443)$ than MODIS Aph. Thus, the empirical MODIS $\mathrm{Chl}$ product was registering the combined influence of phytoplankton pigments and other optically active materials (detritus and CDOM) in the TWS, similar as that found in the South Pacific Gyre (Lee et al., 2010b). Using analytically derived Aph from MODIS measurements to study phytoplankton dynamics is thus further justified. 

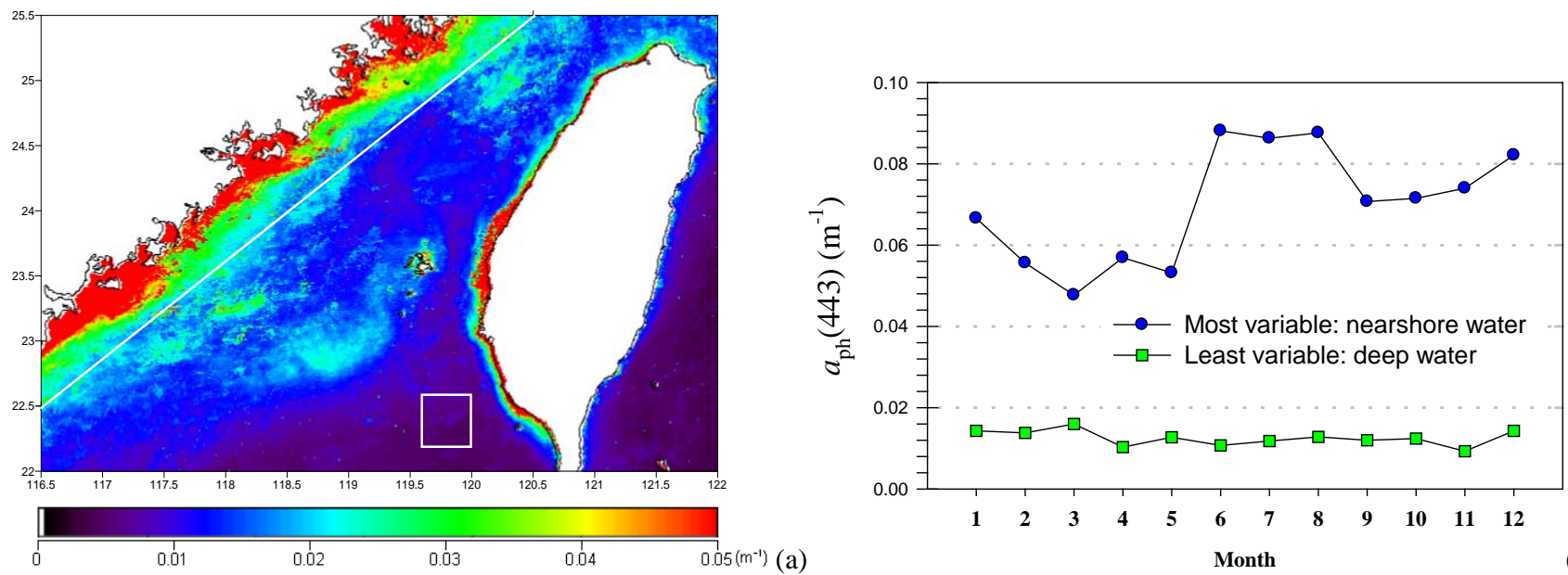

(b)

Fig. 4. (a) Annual mean standard deviation of Aph; (b) the annual cycle of Aph in the most variable coastline (west of the white line alongshore on a) and least variable deep water (the square at the right bottom of a) areas.

\section{Spatio-temporal variation of MODIS Aph in the Taiwan Strait}

The monthly mean of each year and climatological monthly mean MODIS Aph dataset were used to analyze the spatiotemporal variations of Aph during 2003-2009.

First, the annual mean Aph and its standard deviation (STD) were derived from the climatological monthly mean MODIS Aph. The STD identifies a highly variable area located alongshore the China mainland, and an area showing low temporal variation located in the deepest zone of the TWS (i.e. the Penghu Channel), adjacent to the South China Sea (Fig. 4a).

To investigate further the seasonality of Aph in waters of low temporal variation, we chose a square in the Penghu Channel (right bottom of Fig. 4a) and derived its monthly time series. Although variations are weak, Aph slightly increases during December to March by about $17 \%$ over the mean level of Aph in the other months (Fig. 4b). This seasonal pattern with a winter maximum is similar to in situ observations of $\mathrm{Chl}$, phytoplankton cell counts, and primary production at SEATS $\left(18^{\circ} \mathrm{N} 116^{\circ} \mathrm{E}\right.$, South East Asian Timeseries Study station, Tseng et al., 2005) and the entire South China Sea (Ning et al., 2004; Chen, 2005). This correspondence between seasonal cycles of phytoplankton pigment in the TWS and the South China Sea is not surprising since this part of the TWS is dominated by the SCSWC (Jan et al., 2002). Enhanced nitrate availability in winter due to enhanced wind-driven vertical mixing is thought to play a role in modulating phytoplankton dynamics in this water (Chen, 2005), although photoacclimation and altered grazing pressure may also be important (Behrenfeld et al., 2005; Behrenfeld, 2010).
In contrast to the Penghu Channel water, Aph is highly variable alongshore the China mainland, influenced by inputs of the Jiulongjiang and Hanjiang Rivers (see locations in Fig. 1) and by upwelling in summer (Hong et al., 2009) and the Zhe-Min Coastal Water in winter (Jan et al., 2002). In the nearshore band west of the white line on Fig. 4a, Aph ranges from $0.048 \mathrm{~m}^{-1}$ in March to $0.088 \mathrm{~m}^{-1}$ in June (Fig. 4b). Overall, Aph peaks in summer (June-August) at a value $64 \%$ higher than the minimum Aph observed in spring (March-May). Summer is the season of peak river flow, which accounts for $44 \%$ of the annual discharge (Sun et al., 2009; http://baike.baidu.com/view/23372.html). Summer is also the season of southwesterly wind, which drives coastal upwelling (Hong et al., 2009). Nearshore phytoplankton blooms, as indexed by the high Aph values, are thus supported by the availability of nutrients provided by both river plumes and upwelling.

A close-up view of this nearshore water in May-August (Fig. 5a) clearly demonstrates the combined impacts of river plumes and upwelling in summer. Out of each estuary, there is a tongue of high Aph (generally $\geq 0.1 \mathrm{~m}^{-1}$ ) advecting northeastward. This feature is most distinct in June (Fig. 5a). In the vicinity of Hanjiang River estuary (also nearby the Dongshan Island), a broad area of especially high Aph is found, relative to values for the Jiulongjiang River estuary. This difference is, in part, due to the volume of Hanjiang River annual flow at $258 \times 10^{9} \mathrm{~m}^{3}$, which is $\sim 80 \%$ higher than the Jiulongiiang River $\left(142 \times 10^{9} \mathrm{~m}^{3}\right)$ (Sun et al., 2009). In addition, a significant upwelling center is located in the vicinity of Dongshan Island (Hong et al., 2009). These combined factors (upwelling and stronger river plume) result in stronger blooms for the Hanjiang River estuary area. 


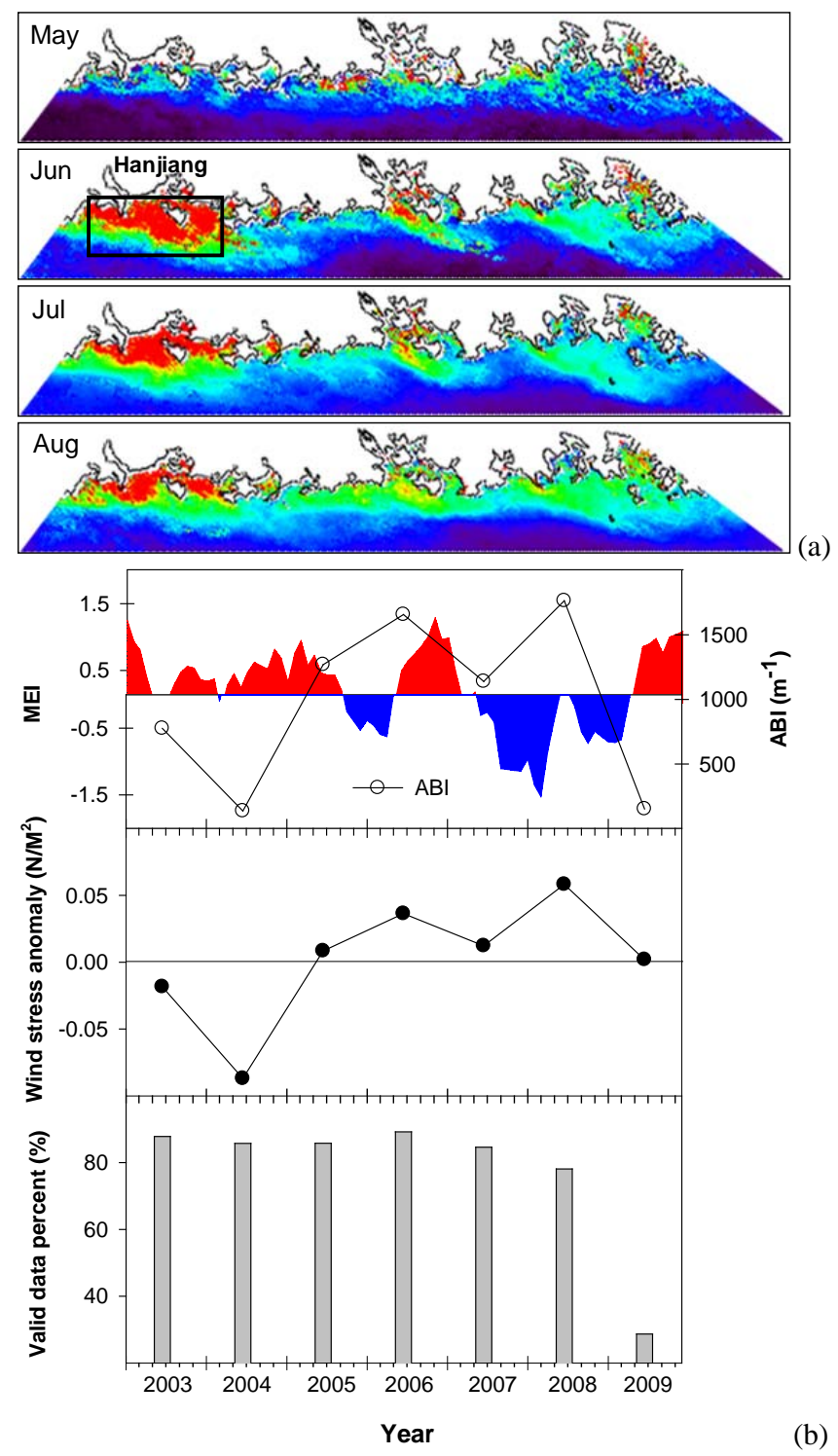

Fig. 5. (a) close-up view of Aph in the nearshore water (west of the white line alongshore on Fig. 4a) in May-August; (b) The interannual variation of Aph percentage of valid retrievals and alongshore wind stress anomaly in the area of Hanjiang River estuary in June during 2003-2009 and the MEI.

To investigate the interannual variation of bloom intensity for such an upwelling enhanced bloom in the Hanjiang River estuary area, we used the monthly mean Aph of each year to derive an annual areal bloom index (ABI). ABI was calculated as the sum of Aph in pixels having Aph $\geq 0.1 \mathrm{~m}^{-1}$ for all valid observations in a month (Aph of $0.1 \mathrm{~m}^{-1}$ corresponds to $\sim 1.7 \mathrm{mg} \mathrm{m}^{-3} \mathrm{Chl}$ in the TWS, Dong, 2010). The ABI within a square representing the Hanjiang River estuary (see location on the June image of Fig. 5a; its area is $9400 \mathrm{~km}^{2}$ ) in June of each year during 2003-2009 is shown in Fig. 5b (the empty circle), along with the percentage of

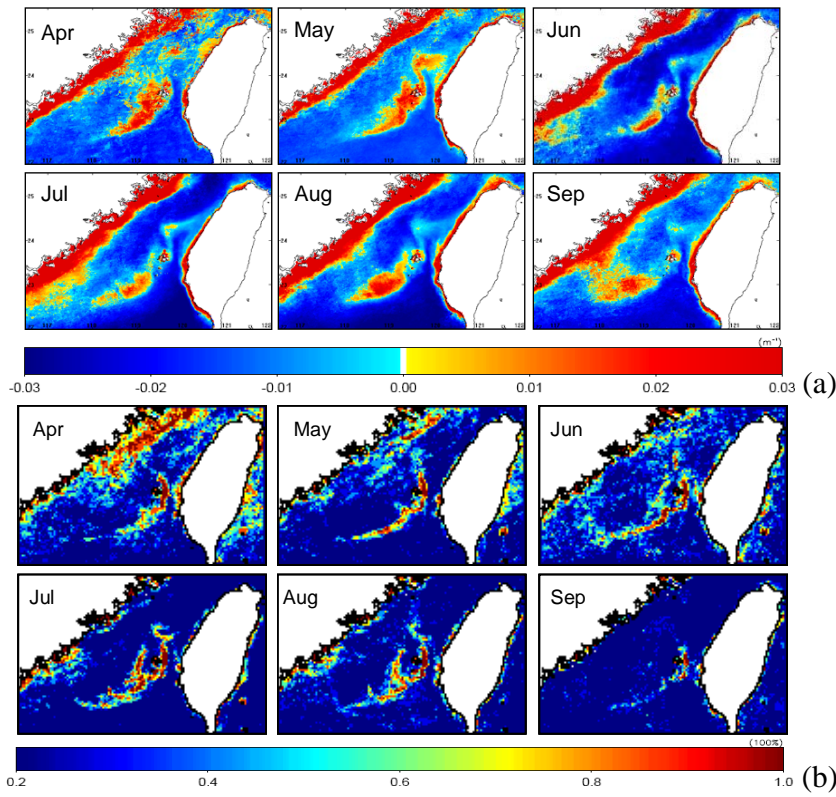

Fig. 6. (a) Spatial anomaly of Aph in the TWS in April-September; (b) thermal frontal probability in April-September.

valid pixels to retrieve the ABI (the grey bar), the alongshore wind stress anomaly (the solid circle), and the Multivariate ENSO Index (MEI, http://www.cdc.noaa.gov/people/ klaus.wolter/MEI/; the red and blue curve indicates occurrence of El Niño and La Niña, respectively). The ABI peaks in 2008 and is the lowest in 2004, and is well correlated with the alongshore wind stress anomaly $\left(R^{2}=0.67\right.$, $n=7$ ). More positive alongshore wind stress anomalies correspond to stronger southwesterly winds, which drive enhanced upwelling, offshore advection of river plumes, and stronger phytoplankton blooms (and vise versa). However, the ABI in 2009 is $152 \mathrm{~m}^{-1}$, even lower than the ABI in $2003\left(776 \mathrm{~m}^{-1}\right)$. The alongshore wind stress anomaly is positive in 2009 and negative in 2003, suggesting bloom favoring conditions in 2009 compared to 2003. This abnormally low number in 2009 is in part due to missing satellite data in the Hanjiang River estuary area owing to heavy cloud cover. In total, there are 7771 pixels in the square for ABI estimation. As the grey bar in Fig. 5b shows, during most of the year, more than $80 \%$ of the pixels in the square have valid retrievals; while in 2009, only $29 \%$ of the pixels had valid Aph data. Therefore, additional uncertainties of satellite data due to bad weather conditions must be noted, necessitating careful examination of the data. If we remove data from 2009 where ABI values are abnormally low in number, the $R^{2}$ between $\mathrm{ABI}$ and the alongshore wind stress anomaly increases to $0.97(n=6)$.

Interestingly, variations of the ABI show coincidence with ENSO activities, illustrated by the match of the empty circles (ABI) and the red and blue curve (MEI) (Fig. 5b). The year 
of the lowest ABI (2004) is in the midst of an El Niño event (2000-2005), and the year of the highest ABI (2008) is in the midst of a La Niña event (2007-2009). Such an ABI difference between El Niño and La Niña years might be more significant, if it is influenced by potential differences in cloud cover between El Niño and La Niña years, since $78 \%$ of the total pixels have valid retrievals in 2008 while the percentage of valid retrievals is as high as $86 \%$ in 2004 (see the grey bar in Fig. 5b). It has been acknowledged that the relationship between the Asian monsoon and ENSO is mutual but selectively interactive (e.g. Webster and Yang, 1992). However, which factor is the underlying cause and which is the effect remain unclear (e.g. Kinter III et al., 2002). Here we have observed a strong coastal bloom in 2008, when the southwest monsoon is the strongest (during 2003-2009) and a La Niña event is occurring. We have also observed a weak bloom in 2004, when the southwest monsoon is the weakest (during 2003-2009) and an El Niño event is at its mid-point. Further study of regional scale ecosystem variability should advance understanding of the monsoon-ENSO interaction.

Spatial anomalies of Aph also highlight a distinctly high Aph patch generally located in the middle of the southern TWS, appearing in the period of April to September (Fig. 6a). This patch is likely associated with (1) shelf break upwelling in the vicinity of the Taiwan Bank (Li et al., 2000), (2) island stirring around Penghu Islands (Simpson and Tett, 1986) and (3) upwelling associated with Zhangyun Ridge (Pi and $\mathrm{Hu}, 2010)$. Frontal probabilities derived from MODIS SST during 2003-2009 are greater than 60\% in the area corresponding to this Aph patch (Fig. 6b). Since vertical temperature gradients are smaller during cold seasons, these fronts can only be well developed in the surface water during warm seasons (April-September). Fronts provide powerful physical forcings to inject nutrients from deep water into the surface, thus facilitating phytoplankton growth.

\section{Conclusions}

The current study provided both an assessment of algorithm performance and a description of phytoplankton dynamics in the optically complex TWS. Based on our analysis of 104 in situ measurements in the TWS, we found that the QAA algorithm provided a satisfactory assessment of $a_{\mathrm{ph}}$ from both MODIS and ship borne $R_{\mathrm{rs}}$. We further derived climatological monthly mean Aph (2003-2009) from MODIS $R_{\mathrm{rs}}$ with QAA and found a variety of seasonal patterns for Aph in the TWS. The most interesting result is that the phytoplankton bloom in the vicinity of Hanjiang River estuary, which is enhanced by upwelling in summer, shows an order of magnitude variation during 2003-2009. This interannual variability is highly correlated with alongshore wind stress anomalies and ENSO activities, and demonstrates ecological responses to changes in environmental forcings, documented here for the first time by using satellite Aph data. These dy- namics were not revealed when satellite Chl product was employed, as there are large uncertainties in the spectral-ratio derived Chl in nearshore waters (Zhang, 2006). It should be noted, however, that Aph is not a full reflection of variability in phytoplankton pigmentation because of the package effect (Bricaud et al., 1998), even though they are directly related to each other. Some uncertainties also remain in our satellite $a_{\mathrm{ph}}$ products due to issues with variable cloud cover that may introduce biases in our results, especially in winter. Repeated observations from multi-sensors and geostationary satellites may help resolve such problems in the future.

Acknowledgements. This work was supported jointly by the Hightech R \& D program of China (\#2008AA09Z108), NSF-China (\#40976068), the National Basic Research Program of China (\#2009CB421200 and 2009CB421201), the China Scholarship Council, and the Program of ITDU (\#B07034). Support for M. Behrenfeld was provided through the National Aeronautics and Space Administration (\#NNX08AF73A). Q. Dong and Z.-P. Lee were partially supported by NASA (\#NNX09AV97G) and the Northern Gulf Institute (\#NA06OAR4320264). We thank the crew of the R/V Yanping II, and J. Wu, X. Ma, X. Sui, W. Zhou, W. Wang, M. Yang, C. Du and G. Wei for their help in collecting in situ data and Allen Milligan and Toby Westberry for helpful discussions during our analysis. We also thank two anonymous reviewers and the editor for their critical comments.

Edited by: A. Bricaud

\section{References}

Behrenfeld, M. J.: Abandoning Sverdrup's Critical Depth Hypothesis on phytoplankton blooms, Ecology, 91, 977-989, 2010.

Behrenfeld, M. J., Boss, E., Siegel, D. A., and Shea, D. M.: Carbon-based ocean productivity and phytoplankton physiology from space, Global Biogeochem. Cy., 19, GB1006, doi:10.1029/2004GB002299, 2005.

Bricaud, A., Morel, A., Babin, M., Allali, K., and Claustre, H.: Variations of light absorption by suspended particles with chlorophyll a concentration in oceanic (case 1) waters: Analysis and implications for bio-optical models, J. Geophys. Res., 103, 31033-31044, 1998.

Carder, K. L., Steward, R. G., Harvey, G. R., and Ortner, P. B.: Marine humic and fulvic acids: their effects on remote sensing of ocean chlorophyll, Limnol. Oceanogr., 34, 68-81, 1989.

Chang, Y., Shimada, T., Lee, M. A., Lu, H. J., Sakaida, F., and Kawamura, H.: Wintertime sea surface temperature fronts in the Taiwan Strait, Geophys. Res. Lett., 33, L23603, doi:10.1029/2006GL027415, 2006.

Chen, L.: Spatial and seasonal variations of nitrate-based new production and primary production in the South China Sea, DeepSea. Res. Pt. I, 52, 319-340, 2005.

Cullen, J. J.: The deep chlorophyll maximum: Comparing vertical profiles of chlorophyll a, Can. J. Fish. Aquat. Sci., 39, 791-803, 1982.

Dong, Q.: Derivation of Phytoplankton Absorption Properties from Ocean Color and Its Application, Ph.D. thesis, Xiamen University, China, 2010. 
Dong, Q., Hong, H., and Shang, S.: A new approach to correct for pathlength amplification in measurements of particulate spectral absorption by the quantitative filter technique, Journal of Xiamen University (Natural Science), 47, 556-561, 2008 (in Chinese, with English abstract).

Du, C., Shang, S., Dong, Q., Hu, C., and Wu, J.: Characteristics of Chromophoric Dissolved Organic Matter in the nearshore waters of the western Taiwan Strait, Estuar. Coast. Shelf. S., 88, 350356, 2010.

Gordon, H. R.: Normalized water-leaving radiance: revisiting the influence of surface roughness, Appl. Optics, 44, 241-248, 2005.

Gordon, H. R., Brown, O. B., Evans, R. H., Brown, J. W., Smith, R. C., Baker, K. S., and Clark, D. K.: A semianalytic radiance model of ocean color, J. Geophys. Res., 93, 10909-10924, 1988.

Guo, L., Hong, H., Chen, J., and Hong, L.: Distribution and variation of suspended matter in the southern Taiwan Strait, in: Minnan-taiwan bank fishing ground upwelling ecosystem study, edited by: Hong, H., 273-281, 1991 (in Chinese, with English abstract).

Hirawake, T., Takao, S., Horimoto, N., Ishimaru, T., Yamaguchi, Y., and Fukuchi, M.: A phytoplankton absorption-based primary productivity model for remote sensing in the Southern Ocean, Polar Biol., 34, 291-302, 2011.

Hong, H., Wu, J., Shang, S., and Hu, C.: Absorption and fluorescence of chromophoric dissolved organic matter in the Pearl River Estuary, South China, Mar. Chem., 97, 78-89, 2005.

Hong, H., Zhang, C., Shang, S., Huang, B., Li, Y., Li, X., and Zhang, S.: Interannual variability of summer coastal upwelling in the Taiwan Strait, Cont. Shelf. Res., 29, 479-484, 2009.

International Ocean-Colour Coordinating Group (IOCCG): Remote sensing of inherent optical properties: Fundamentals, tests of algorithms, and applications, in: Reports of the International Ocean-Colour Coordinating Group, No. 5, edited by: Lee, Z., Dartmouth, Canada, 2006.

Jan, S., Wang, J., Chern, C. S., and Chao, S. Y.: Seasonal variation of the circulation in the Taiwan Strait, J. Marine Syst., 35, 249268, 2002

Kiefer, D. A. and SooHoo, J. B.: Spectral absorption by marine particles of coastal waters of Baja California, Limnol. Oceanogr., 27, 492-499, 1982.

Kinter III, J., Miyakoda, K., and Yang, S.: Recent change in the connection from the Asian monsoon to ENSO, J. Climate, 15, 1203-1215, 2002.

Kishino, M., Takahashi, M., Okami, N., and Ichimura, S.: Estimation of the spectral absorption coefficients of phytoplankton in the sea, B. Mar. Sci., 37, 634-642, 1985.

Lee, Z., Carder, K. L., Marra, J., Steward, R. G., and Perry, M. J.: Estimating primary production at depth from remote sensing, Appl. Optics, 35(2), 463-474, 1996.

Lee, Z., Carder, K. L., and Arnone, R. A.: Deriving inherent optical properties from water color: a multiband quasi-analytical algorithm for optically deep waters, Appl. Optics, 41, 5755-5772, 2002.

Lee, Z., Lubac, B., Werdell, J., and Arnone, R.: An update of the Quasi-Analytical Algorithm (QAA_v5), available at: http: //www.ioccg.org/groups/Software_OCA/QAA_v5.pdf, 2009.

Lee, Z., Ahn, Y., Mobley, C., and Arnone, R.: Removal of surface-reflected light for the measurement of remote-sensing reflectance from an above-surface platform, Opt. Express, 18(25),
26313-26342, 2010a.

Lee, Z., Shang, S., Hu, C., Lewis, M., Arnone, R., Li, Y., and Lubac, B.: Time series of bio-optical properties in a subtropical gyre: Implications for the evaluation of inter-annual trends of biogeochemical properties, J. Geophys. Res., 115, C09012, doi:10.1029/2009JC005865, 2010b.

Li, C., Hu, J., Jan, S., Wei, Z., Fang, G. H., and Zheng, Q.: Winterspring fronts in Taiwan Strait, J. Geophys. Res., 111, C11S13, doi:10.1029/2005JC003203, 2006.

Li, L., Guo, X., and Wu, R.: Oceanic fronts in southern Taiwan Strait, Journal of Oceanography in Taiwan Strait, 19, 147-156, 2000 (in Chinese, with English abstract).

Marra, J., Trees, C. C., and O'Reilly, J. E.: Phytoplankton pigment absorption: A strong predictor of primary productivity in the surface ocean, Deep-Sea. Res. Pt. I, 54, 155-163, 2007.

Mélin, F., Zibordi, G., and Berthon, J. F.: Assessment of satellite ocean color products at a coastal site, Remote. Sens. Environ., 110, 192-215, 2007.

Mitchell, B. G., Bricaud, A., and Carder, K.: Determination of spectral absorption coefficients of particles, dissolved material and phytoplankton for discrete water samples, in: Ocean optics protocols for satellite ocean color sensor validation, revision 2, edited by: Fargion, G. S. and Mueller, J. L., Greenbelt, Maryland: NASA Goddard Space Flight Space Center, 125-153, 2000.

Mobley, C. D.: Light and water: Radiative Transfer in Natural Waters, Academic, New York, 1994.

Ning, X., Chai, F., Xue, H., Cai, Y., Liu, C., and Shi, J.: Physicalbiological oceanographic coupling influencing phytoplankton and primary production in the South China Sea, J. Geophys. Res., 109, C10005, doi:10.1029/2004JC002365, 2004.

O'Reilly, J. E., Maritorena, S., Siegel, D., and O'Brien, M. C.: Ocean color chlorophyll a algorithms for SeaWiFS, OC2, and OC4: version 4, in: SeaWiFS postlaunch technical report series, volume 11, SeaWiFS postlaunch calibration and validation analyses, part 3, edited by: Hooker, S. B. and Firestone, E. R., Greenbelt, Maryland: NASA Goddard Space Flight Center, 923, 2000.

$\mathrm{Pi}, \mathrm{Q}$. and $\mathrm{Hu}, \mathrm{J}$. : Analysis of sea surface temperature fronts in the Taiwan Strait and its adjacent area using an advanced edge detection method, Science China, Earth Sci., 53, 1008-1016, 2010.

Sathyendranath, S., Hoge, F. E., Platt, T., and Swift, R. N.: Detection of phytoplankton pigments from ocean color: Improved algorithms, Appl. Optics, 33, 1081-1089, 1994.

Simpson, J. H. and Tett, P.: Island steering effects on phytoplankton growth, in: Lecture notes on coastal and estuarine studies, edited by: Bowman, J., Yentsch, M., and Peterson, W. T., Berlin, 41-76, 1986.

Stewart, R. H.: Introduction to physical oceanography, Department of Oceanography, Texas A \& M University, 2008.

Stuart, V., Sathyendranath, S., Platt, T., Maass, H., and Irwin, B.: Pigments and species composition of natural phytoplankton populations: effect on the absorption spectra, J. Plankton Res., 20, 187-217, 1998.

Sun, B., Zhou, G., Wei, H., Liu, Z., and Zeng, D.: The flux of river active material flowing into the sea: Preliminary achievements, Earth Science Frontiers, 16, 361-368, 2009 (in Chinese, with English abstract).

Tassan, S. and Ferrari, G. M.: An alternative approach to absorption 
measurements of aquatic particles retained on filters, Limnol. Oceanogr., 40, 1358-1368, 1995.

Tassan, S. and Ferrari, G. M.: A sensitivity analysis of the "Transmittance-Reflectance" method for measuring light absorption by aquatic particles, J. Plankton. Res., 24, 757-774, 2002.

Tseng, C. M., Wong, G. T. F., Lin, I. I., Wu, C. R., and Liu, K. K.: A unique seasonal pattern in phytoplankton biomass in low-latitude waters in the South China Sea, Geophys. Res. Lett., 32, L08608, doi:10.1029/2004GL022111, 2005.

Wang, D. X., Liu, Y., Qi, Y. Q., and Shi, P.: Seasonal variability of thermal fronts in the northern South China Sea from satellite data, Geophys. Res. Lett., 28, 3963-3966, 2001.

Webster, P. and Yang, S.: Monsoon and ENSO: Selectively interactive systems, Q. J. Roy. Meteor. Soc., 118, 877-926, 1992.

Westberry, T., Behrenfeld, M. J., Siegel, D. A., and Boss, E.: Carbon-based primary productivity modeling with vertically resolved photoacclimation, Global. Biogeochem. Cy., 22, GB2024, doi:10.1029/2007GB003078, 2008.
Yelland, M. J. and Taylor, P. K.: Wind stress measurements from the open ocean, J. Phys. Oceanogr., 26, 541-558, 1996.

Yelland, M. J., Moat, B. I., Taylor, P. K., Pascal, R. W., Hutchings, J., and Cornell, V. C.: Wind stress measurements from the open ocean corrected for airflow distortion by the ship, J. Phys. Oceanogr., 28, 1511-1526, 1998.

Zhang, C., Hu, C., Shang, S., Muller-Karger, F. E., Li, Y., Dai, M., Huang, B., Ning, X., and Hong, H.: Bridging between SeaWiFS and MODIS for continuity of chlorophyll- $a$ concentration assessments off Southeastern China, Remote. Sens. Environ., 102, 250-263, 2006.

Zhang, C. Y.: Response of chlorophyll a to marine environment variability on multiple time scales in the Taiwan Strait, Ph.D. dissertation, Xiamen University, China, 2006. 